Hene, B.T. et al. (2017). Variation in the daily activity, movement and refugia of Critically

Endangered geometric tortoises, Psammobates geometricus, in autumn and spring.

Africa Journal of Herpatology, 2017: 1-14.

http://dx.doi.org/10.1080/21564574.2017.1331935

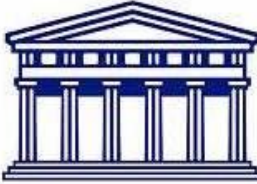

UNIVERSITY of the

WESTERN CAPE

\title{
Variation in the daily activity, movement and refugia of Critically Endangered geometric tortoises, Psammobates geometricus, in autumn and spring
}

Brian T. Henen, Ulric P. van Bloemestein, Margaretha D. Hofmeyr and Craig A. Weatherby

\begin{abstract}
To help assess habitat requirements of Critically Endangered geometric tortoises, we used thread-trailing to measure daily activity, movements and refugia of adult Psammobates geometricus in autumn and spring 2002. We found strong differences between seasons, and effects of weather, individuals and sex. The high activity was consistent with mild weather during autumn and spring. However, daily temperatures limited female movements on cool autumn days and male movements on warm spring days, a pattern consistent with sexual size dimorphism (large females and small males). The long movements in autumn probably helped tortoises find food plants that grow quickly after autumn rains; both sexes recover body condition from autumn lows, and females begin egg production in late-autumn and winter. These movements may also help males mate with females before they ovulate. The high activity of females in spring should help them forage and sustain their vitellogenesis, egg production and nesting in spring. Male paths tended to be more linear than female paths in both seasons, so this sexual difference is likely not linked to food consumption. Males may move long, linear paths to engage females and avoid other males. Males may have been thermally-challenged in spring. Their movements decreased with increased ground temperatures (in the sun), they used denser refugia in spring than in autumn, and in spring used denser refugia than females used. Geometric tortoises typically used different refugia on consecutive nights, a type of predator avoidance mechanism.
\end{abstract}

\section{INTRODUCTION}

Geometric tortoises Psammobates geometricus are Critically Endangered (Hofmeyr and Baard 2015) because of a multitude of anthropogenic factors, including massive loss of habitat (c. 97\%; Baard 1993, 1995), an unnatural increase in fire frequency, predation by subsidised predators (e.g. Chacma baboons and Pied Crows), poaching (Henen et al. 2013), and highly fragmented habitat resulting in small populations vulnerable to stochastic impacts such as fire (Baard 1995). The dire conservation status prompted establishment of reserves (Baard 1988) and research on the species' biology (Baard 1988, 1995; Henen et al. 2005, 
2013; Hofmeyr et al. 2012). Our knowledge of P. geometricus habitat require ments and use is central to our ability to conserve them (Hofmeyr et al. 2006, 2012).

In spring and autumn 2002, we used thread-trailing (Breder 1927; Hailey 1989; DiazPaniagua et al. 1995) to quantify how adult P. geometricus use their habitat. Although geometric tortoises are active year-round (Boycott \& Bourquin 2000; Hofmeyr et al. 2012), they are most active in autumn and spring, between the warm, dry summers and cool, wet winters. Winter rain stimulates the primary productivity that forms P. geometricus' food and refugia, so contrasting autumn and spring activity, movements and refugia should help us detect important seasonal differences in habitat use and requirements. Consequently, we hypothesised that there would be seasonal changes in daily activity, distance moved (walked), displacement (straight-line distance moved), the ratio of displacement to distance (DDR) and the types of refugia used.

Like other tortoise species (Nagy \& Medica 1986; Hailey 1989; Lagarde et al. 2002; Keswick \& Hofmeyr 2014; and many others), geometric tortoises are ectotherms that depend on adequate body temperature to perform daily functions, from becoming active to moving, foraging, reproducing and metabolising. Consequently, we also tested whether activity and movements varied with weather variables (e.g. air and ground temperatures). The logistics of thread-trailing requires many detailed measurements during late-afternoon light and twilight after tortoises settle in refugia, so our sample size was limited to only four males and five females. Consequently, our tests for effects of sex, body size and body condition are tenuous and exploratory.

\section{Materials and Methods \\ General Design}

We studied adult male and female geometric tortoises in Alluvium Fynbos, which had burned four years earlier (1998; Hofmeyr et al. 2012), for 15 days in autumn (22 April to 6 May) and 20 days in spring (12 to 31 October) 2002. In mid-April 2002 we surveyed the area, weighed each adult $( \pm 0.1 \mathrm{~g})$ with an Ohaus digital balance, and used vernier callipers $( \pm 0.1$ $\mathrm{mm}$ ) to measure carapace length (the horizontal, midline distance from the nuchal to supracaudal scutes), shell width (at marginal scutes six or seven) and shell height (to the top of the third vertebral scute). We estimated tortoise volume as an ellipsoid (in $\mathrm{cm}^{3}, \pi \times$ carapace length $\times$ shell width $\times$ shell height $/ 6$ ooo; Loehr et al. 2004), and body condition indices as body mass divided by volume. In autumn, we studied six adults, three males and three females. In spring, we studied nine adults, four males and five females, using three males and two females in both seasons.

\section{Thread-trailing}

The thread trailers were $6 \mathrm{~g}$ plastic film canisters with a hole that allowed the thread to unwind as tortoises walked. We used contact adhesive and duct tape to attach the canister between the fifth vertebral and supracaudal scutes, placed a 150-m spool of cotton thread inside the canister and closed the canister lid. We returned individuals to their exact capture 
sites, and tied the thread to the refuge plant or a cane staked near the tortoise, using different coloured threads to distinguish individual tortoise trails. We excluded data from the first 24 to $48 \mathrm{~h}$ to standardise starting dates and avoid potential handling effects.

We recorded data after tortoises had settled in refugia, c. 16:30 to 19:00 h. We recorded the tortoise's location with a handheld GPS unit and tied the thread to the new refuge or cane. We used movement distances to estimate when to replace thread spools via the canister lid. Tortoises rarely moved, and less than a couple of metres if they moved, when we replaced the thread. We considered a tortoise active if it moved a detectable distance during the day, and calculated daily activity as the percentage of animals active.

\section{Distance, Displacement and Movement Path (Shape)}

We measured daily movement distance $(\mathrm{m})$ by pacing, with calibrated paces, the length of thread between the previous and current refuge. We quantified daily displacement $(\mathrm{m})$ as the straight-line distance between the previous and current refuge, via pacing (autumn) or a Laser Rangefinder (spring; Bushnell Yardage Pro 500). We excluded inactive tortoises when calculating daily averages for distance, displacement, and the displacement-to-distance ratios (DDR). Small DDR indicate an intense use of habitat near the refuge. Large DDR represent a long or linear displacement. Displacement and DDR equalled zero for active tortoises that returned to the same refuge.

The shape of a tortoise's thread trail informs us of movement patterns and habitat use. In spring 2002, after pacing and inspecting a path, we assigned the path to one of six shape categories (Table 1). These categories represent a transition from linear, directional movement to apparent non-directional movements (e.g. criss-cross) or a circular shape.

\section{Refugia and Environmental Data}

We measured refuge plant height and width $(\mathrm{c} . \pm 1 \mathrm{~cm})$ to estimate refuge volume as an ellipsoid (in litres, $\pi \times$ height $\times$ width $^{2} / 6$ ooo; for plants wider than tall, we squared the height not the width). Each refuge was assigned a density index between one and five indicating $20 \%$ to full cover (tortoise essentially not visible and with no exposure to sunlight), respectively. When two plant species formed the refuge, we analysed data for the species that provided the most cover. For data analyses, we used four refuge categories: grass, restio (a rush-like plant characteristic of fynbos vegetation), sedge and shrub. 
Table 1. Shape of the daily movement paths of Psammobates geometricus.

\begin{tabular}{ll}
\hline Category & \multicolumn{1}{c}{ Description } \\
\hline Linear (L) & A nearly straight, directional movement \\
Semi-circular (SC) & A curved but directional movement with a semi-circular to semi-oval shape \\
Zigzag (Z) & A directional movement with various deviations to the left and right, but the \\
& path never or seldom crossed
\end{tabular}

We used an MCS 120-04EX automatic data logger (MC Systems, Cape Town, South Africa) to collect meteorological data that we averaged for 15 -min. intervals. We used thermocouples (MCS 151) to measure air temperature (shaded, ${ }^{\circ} \mathrm{C}$ ), ground temperature in full sun, and ground temperature in full shade of Renosterbos (Elytropappus rhinocerotis). We recorded solar radiation $\left(\mathrm{W} \mathrm{m}^{-2}\right.$ ) with a pyranometer (MCS 155-1; 95\% of the full range of the solar spectrum) and percent humidity with a MCS 174 relative humidity probe. Except for ground temperatures, environmental parameters were recorded at a height of $0.75 \mathrm{~m}$. We noted local rainfall events and summarised environmental results as daylight means, maxima and minima for the 12 hours (07:00 to 19:00 $\mathrm{h}$ ) bracketing the periods of tortoise activity.

\section{Statistics}

We report daily activity (\% of tortoises active), distance, displacement, DDR, body size, body condition, refuge size and refuge density as means $\pm 95 \% \mathrm{CI}$, considered tests significant if $P<$ 0.05, and compared seasonal means with parametric tests (Student's or paired $t$-tests) or their non-parametric equivalents (Mann-Whitney or Wilcoxon signed rank tests) if the data would not transform via logarithmic, square root and rank transformations. We also used two-way ANOVA to test for main effects and interactions of season and sex; we followed ANOVA with Student-Newman-Keuls (SNK) post hoc comparisons. For two-way ANOVA data that would not transform, we used 2 one-way ANOVA (parametric or Kruskal-Wallis ANOVA). All of these results were strong enough to obviate Bonferroni corrections, but we used the Bonferroni criterion $P=0.00417$ for comparisons of refuge volumes and densities between seasons for each sex. The use of two-way ANOVA and two-way repeated measures ANOVA to evaluate individual tortoise and day effects on distance, displacement and DDR were exploratory due to the relatively small number of tortoises. Tortoises used only one sedge refuge in each season, so we excluded sedges from ANOVA.

The frequencies of movement path shapes and refuge types were compared among seasons and sexes using contingency table analyses ( $\chi^{2}$; Zar 1999). Within a season or sex, we used simple $\chi^{2}$ tests to compare frequencies to a homogeneous distribution. 
We used Spearman's rank order correlations $\left(r_{\mathrm{S}}\right)$ to test for relationships between daily measures (percent activity and average distance, displacement and DDR) and environmental variables. Ground temperature in the sun $\left(T_{g}-\mathrm{sun}\right)$ most consistently revealed significant correlations and no spurious correlations. Unlike other days in spring, 18 October 2002 was cool and rainy (Fig. 1) and tortoises moved short distances. This movement fell outside of the $99 \%$ prediction intervals relating movement to $\mathrm{Tg}$-sun, so we excluded this day's results from the final regressions. We also tested correlations between seasonal averages for individuals (e.g. percent activity and daily distance) and individual, seasonal body mass, size (i.e. length, width, height and volume) and condition.

\section{Results}

\section{Activity, Distance and Displacement}

Average daily activity was high (84\%; Fig. 2a), but varied considerably in autumn (40 to $100 \%$ ) and spring (56 to 100\%). Although activity did not differ between seasons (all Mann-Whitney $T_{15,20}<300$ and $P>0.35$ ), in spring, females were more active than males (Fig. 2a).

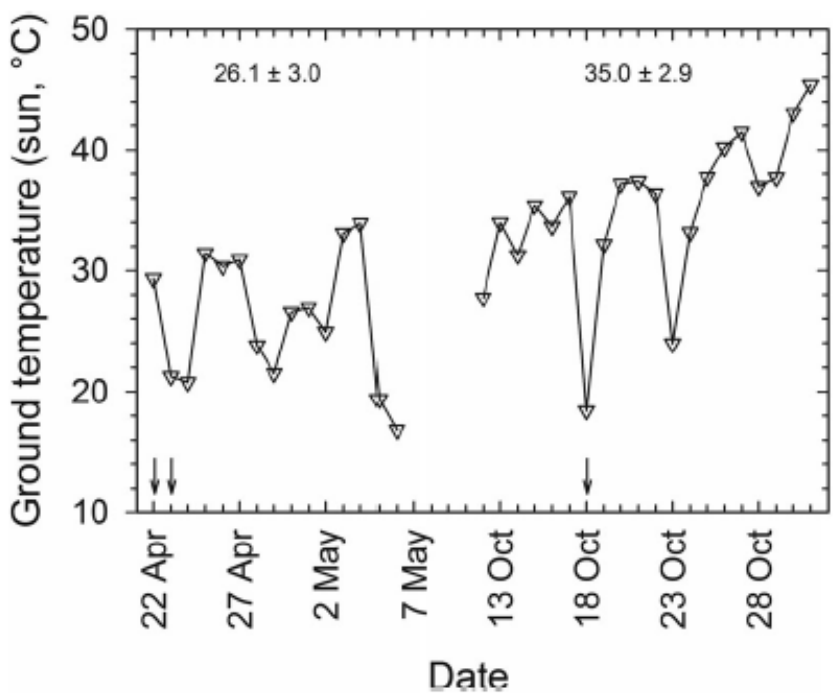

Figure 1. Mean ground temperature in the sun $\left(T_{\mathrm{g} \text {-sun }}\right)$ during 15 days in autumn (22 April to 6 May) and 20 days in spring (12 October to 31 October) 2002. Day length was $10.8 \mathrm{~h}$ and $13.1 \mathrm{~h}$ in autumn and spring, respectively (Time and Date AS 2016). $T_{\mathrm{g} \text {-sun }}$ was higher in spring than in autumn $\left(t_{33}=\right.$ $4.41, P<0.001$ ), with means and $95 \% \mathrm{CI}$ indicated at the top of the figure. Arrows indicate dates when rain fell on site.

When active, geometric tortoises travelled $49.7 \mathrm{~m}$ per day $( \pm \mathrm{CI}=8.15, n=35$ for both seasons) and moved further in autumn than in spring (autumn: $62.2 \pm 13.6 \mathrm{~m} \mathrm{~d}^{-1}, n=15$ and spring: $40.3 \pm 8.7 \mathrm{~m} \mathrm{~d}^{-1}, n=20, t_{33}=3.01, P=0.005$; Fig. $2 b$ ); the seasonal result was consistent with two-way ANOVA $\left(F_{1,201}=13.9, P<0.0005\right)$. Female displacement per day did not differ between seasons $\left(t_{32}=1.96 ; P=0.058\right)$ but males displaced further 
per day in autumn than in spring (Fig. 2c). In each season, males displaced further than females displaced.

Exploratory, repeated measures ANOVA showed strong effects of days and individuals on distances and displacements (all $F>2.90$ and $P<0.001$; $\mathrm{df}=8,164$ for individuals, and $\mathrm{df}=$ 34, 164 for days). The post hoc comparisons indicate that the second shortest distance occurred on 18 October $2002(18.6 \pm 17.0 \mathrm{~m})$, an unusually cool, rainy day (Fig. 1), the longest distance was on 26 April $2002(126.3 \pm 40.8 \mathrm{~m})$, a warm day after a cool rainy spell (Fig. 1), and one male's average displacement was the largest $\left(61.7 \pm 12.8 \mathrm{~m} \mathrm{day}^{-1}, n=\right.$ 33 ). Body condition was higher in spring than in autumn (two-way ANOVA $F_{1,11}=30.2, P$ < 0.0005; see Online Supplementary Material, Table S1), but neither activity, daily distance $\left(\mathrm{m} \mathrm{day}^{-1}\right)$, total distance ( $\mathrm{m}$, per season) nor daily displacement correlated to body condition, size or mass (all $r_{\mathrm{S}} \leq 0.60$ and $P>0.075, n=6$ and 9 for autumn and spring, respectively).

There were few correlations between tortoise movements and environmental data. The daily distances moved (Fig. 3) and displaced (Fig. 4a) by males were inversely related to $T$ g-sun in spring, when air temperatures (spring: $22.3 \pm 1.55{ }^{\circ} \mathrm{C}, n=20>$ autumn: 19.1 $\pm 1.38{ }^{\circ} \mathrm{C}, n=15$ ), ground temperatures and radiation were greater, and relative humidity was lower, than in autumn (Fig. 1 and Fig. S1, all $t_{33}>2.90$ and $P<0.01$ ).

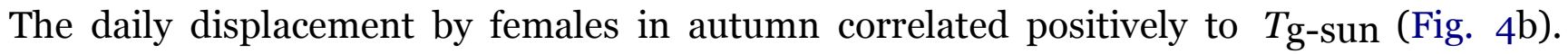
Environmental variables did not correlate with day-length in autumn (all $r_{\mathrm{S}}<0.46$ and $P>0.08$ ) but did in spring (all $P<0.05 ; r_{\mathrm{S}}>0.45$ for temperatures and radiation and $r_{\mathrm{S}}=$ temperatures and radiation correlated positively $\left(r_{\mathrm{S}}=0.54\right.$ to 0.92 and $P=0.037$ to $P<0.0001)$, but correlated inversely with relative humidity $\left(r_{\mathrm{S}}=-0.53\right.$ or stronger, $P$ $=0.04$ to $P<0.0001$ ). 


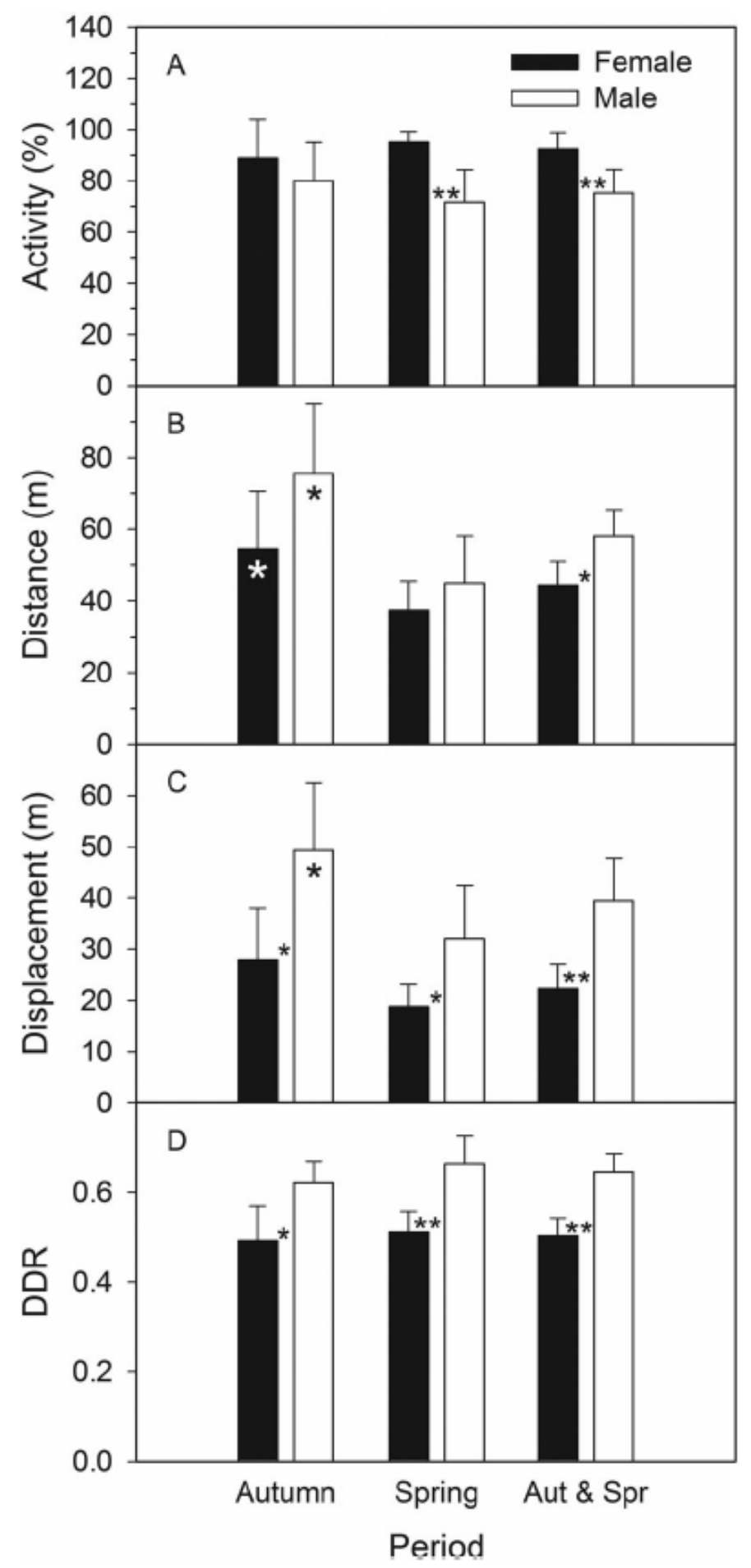

Figure 2. Daily activity (A; \% of animals), distance moved (B), distance displaced (C) and ratio of displacement to distance (D; DDR) for male and female geometric tortoises (Psammobates geometricus) in autumn, spring and both seasons combined in 2002. Values are averages $\pm 95 \%$ CI of daily means. Asterisks between bars indicate sexual differences at $P<0.05\left({ }^{*}\right)$ and $P<0.005(* *)$ from paired $t$-tests; the patterns for continuous variables were confirmed with two-way ANOVA (distance: season, $F_{1,201} \geq 13.21, P<0.001$; displacement, $F_{1,195}>5.49$ and $P<0.025$ for sex and season; DDR, $F_{1,201}=14.88, P<0.001$ for sex). Asterisks within a bar indicate seasonal differences within a sex (Student's $t$-tests). Autumn distances did not differ between males and females (paired $t_{13}=2.06 ; P=0.061$ ). Sample sizes $=15,20$ and 35 for autumn, spring and seasons combined. However, for female distance, displacement and DDR, $n=14$ for autumn. 


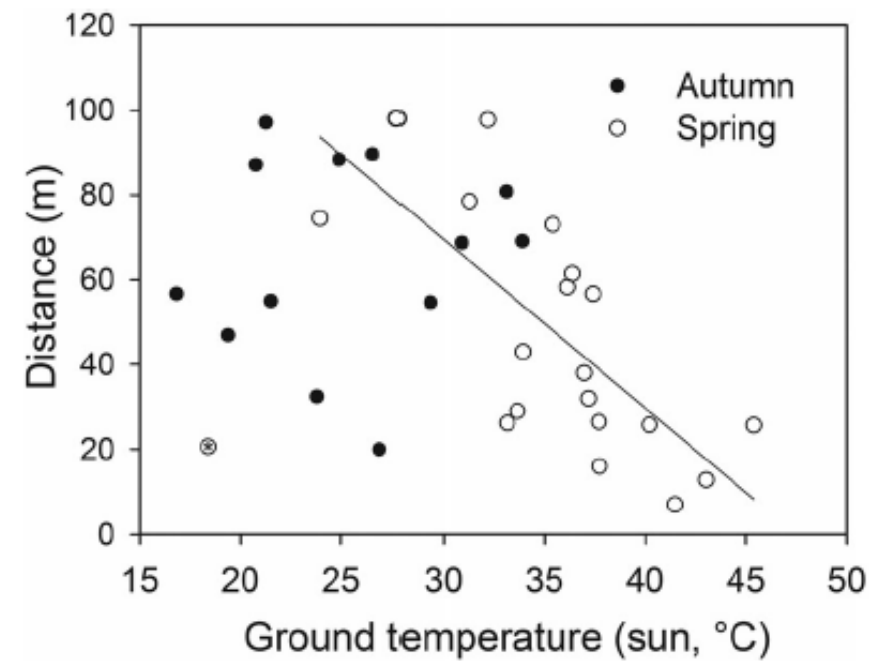

Figure 3. Male Psammobates geometricus distance moved (average per day) in relation to ground temperature in the sun (average during daylight hours) for autumn and spring 2002. The cold, rainy spring day $(*, 18$ October) was an outlier that we excluded from the regression (regression line plotted for spring; distance $=189-3.98 T_{\mathrm{g}-\text { sun }} ; r^{2}=0.519, F_{1,17}=18.4, P<0.001$ ).

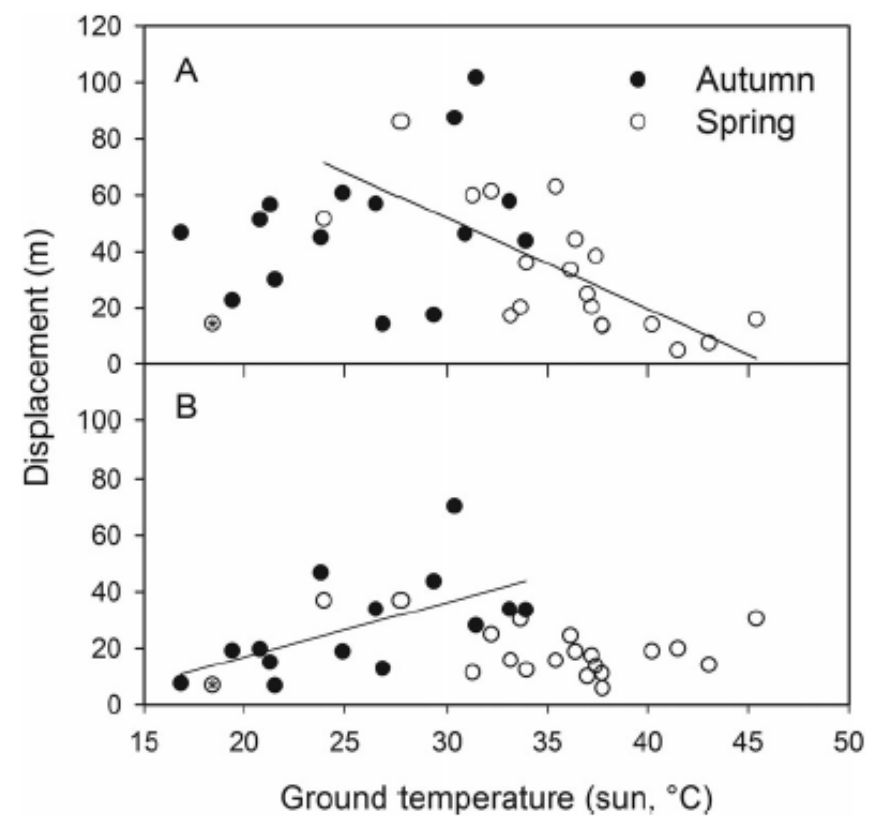

Figure 4. Relationships of male (A) and female (B) displacement (daily averages) of Psammobates geometricus to ground temperature in the sun (average during daylight hours) during autumn (22 April to 6 May) and spring (12 to 31 October) 2002. The relationship was significant for males in spring (displacement $=149-3.23 T_{\text {g-sun }}, r^{2}=0.523, F_{1,17}=18.7, P<0.001$ ) and females in autumn (displacement $=-21.9+1.93 T_{\mathrm{g}-\mathrm{sun}}, r^{2}=0.351, F_{1,12}=6.50, P=0.026$ ). The cold rainy, spring day $(*, 18$ October) was an outlier that we excluded from the regression. 


\section{Displacement-to-Distance Ratio (DDR) and Movement Path Shape}

The mean ( \pm CI) DDR was $0.556 \pm 0.027$ and did not differ between seasons (Fig. 2d), but was greater for males than for females. Separate two-way ANOVA confirmed the sex effect $\left(F_{1,201}\right.$ $=14.9, P<0.001)$, and detected effects of individuals $\left(F_{9,194}=4.66 ; P<0.001\right)$, but there was no effect of individual days $\left(F_{34,161}=1.31, P=0.14\right)$. The post hoc tests among individuals indicated two males had the highest DDR ( $0.696 \pm 0.041$ and $0.666 \pm 0.054)$.

Movement path shapes were not homogeneously distributed in spring $\left(\chi^{2}=17.3, P<0.001\right.$; Fig. 5); circular paths occurred infrequently. Path shapes differed between males and females (contingency $\chi^{2}=16.2, P=0.006$ ). When considering sexes separately, the frequency of female path shapes were homogenous $\left(\chi^{2}=8.11, P<0.25\right)$ and male frequencies were heterogeneous $\left(\chi^{2}=23.9, P<0.001\right)$, with males tending to move linearly and crisscross patterns.

\section{Refuge Use, Size and Density}

Refuge use varied strongly between seasons and sexes (3-way contingency $\chi^{2}=39.1 ; P<$ 0.0001), with grass use high in autumn and shrub use high in spring (Table 2). The high grass use in autumn was primarily due to frequent grass use by males. Conversely, the high shrub use in spring was largely due to frequent shrub use by females. Males used grasses disproportionately more frequently in autumn than in spring, and females used shrubs disproportionately more frequently in spring than in autumn (Table 2).

Among all refuges, autumn refuges were much larger (litres) than spring refuges (Fig. 6A \& B), with two-way ANOVA finding no significant sex or interaction terms (both $F_{1,237}\langle 0.2, P\rangle$ o.65). However, a separate two-way ANOVA on autumn refuge volumes found a strong category effect $\left(F_{2,70}=18.407 P<0.001\right)$, with significant post-hoc differences among all three refuge categories (SNK: grass $>$ restio $>$ shrub), and no significant sex or interaction terms (both $F_{2,70}<0.8$ and $P>0.45$ ). Additional post-hoc results on volumes indicated that female grass refugia were larger than their restio and shrub refugia, and male grass refugia were larger than their shrub refugia (Fig. 6A). The two-way ANOVA for spring refugia volumes found no significant result for the sex, category or interaction of sex and category (sex: $F_{1,159}=0.130, P=0.719$; both category and interaction tests $F_{2,159}<$ 2.35 and $P>0.095$ ).

For refugia, autumn densities were lower than spring densities overall (autumn 2.07 \pm 0.215 , $n=76$; spring $2.45 \pm 0.146, n=165$; Mann-Whitney $U=4770.5, P=0.007$; Fig. $6 \mathrm{C}$ and D) and for males $\left(H_{1}=4.25, P=0.039\right)$, but not for females $\left(H_{1}=0.051, P=0.822\right)$. However, autumn densities were not normal, even after transformations, so we tested within-season effects with Kruskal-Wallis one-way ANOVA on ranks. Autumn refuge density did not differ due to sex $\left(H_{1}=1.856, P=0.173\right)$ but varied among categories $\left(H_{2}=6.614, P=\right.$ 
o.037) with post-hoc results indicating grass refugia being denser than restio refugia (Fig. 6C).

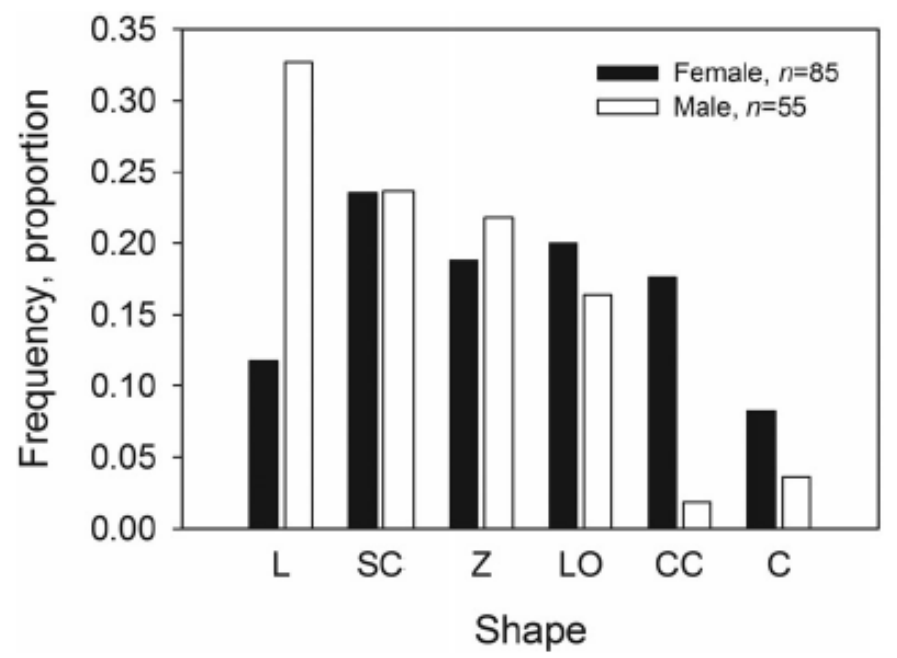

Figure 5. Relative frequency (proportion) of movement shapes for male and female geometric tortoises (Psammobates geometricus) in spring (12 to 31 October) 2002. Shapes include linear (L), semi-circular (SC), zigzag (Z), loops (LO), criss-cross (CC), and circular (C).

Table 2. Percent refuge use for geometric tortoises in autumn and spring 2002. We used absolute frequencies in contingency table tests and simple $\chi^{2}$ tests to evaluate distribution homogeneity. Frequencies were not homogeneous among refuge categories for asterisked rows $(* * *, P<0.0005)$, with ${ }^{\mathrm{L}}$ and ${ }^{\mathrm{H}}$ indicating low and high frequencies, respectively. For a refuge category, frequencies differed between sexes ( ${ }^{\#}$, in autumn), or between seasons ( ${ }^{S}$, for one or both sexes combined).

\begin{tabular}{llllll}
\hline & Shrub & Grass & Restio & Sedge & $n$ \\
\hline Autumn & & & & & \\
Male*** & 25.0 & $63.9^{\mathrm{HHS}}$ & $11.1^{\#}$ & $0.0^{\mathrm{L}}$ & 36 \\
Female & $32.6^{\mathrm{S}}$ & $30.2^{\#}$ & $30.2^{\#}$ & $7.0^{\mathrm{L}}$ & 43 \\
Total*** & $29.1^{\mathrm{S}}$ & $45.6^{\mathrm{SH}}$ & 21.5 & $3.8^{\mathrm{L}}$ & 79 \\
Spring & & & & & \\
Male & 42.1 & $28.9^{\mathrm{S}}$ & 28.9 & $0.0^{\mathrm{L}}$ & 76 \\
Female*** & $54.4^{\mathrm{HS}}$ & 16.7 & 27.8 & $1.1^{\mathrm{L}}$ & 90 \\
Total*** & $48.8^{\mathrm{HS}}$ & $22.3^{\mathrm{S}}$ & 28.3 & $0.6^{\mathrm{L}}$ & 166 \\
\hline
\end{tabular}

In spring, refuge density had normal distributions and showed a strong sex effect (two-way ANOVA: $\left.F_{1,157}=19.42, P<0.001\right)$, no refuge category effect $\left(F_{2,157}=1.903, P=0.153\right)$ and a weak interaction term $\left(F_{2,157}=3.716, P=0.026\right)$. Although male spring refugia were denser than female spring refugia, only grass differed between sexes in post-hoc tests (males > females; Fig. 6D). 


\section{Discussion}

\section{Season}

The autumn-spring contrast for $P$. geometricus requirements were reflected most in distances moved (autumn > spring) rather than in activity. The high activity in autumn and spring was comparable to that for other tortoise species during mild or wet conditions (70-100\%) and greater than the activity measured during more adverse dry, warm or hot conditions (c. 33-50\%: Nagy \& Medica 1986; Wright et al. 1988; Hailey 1989; Diaz-Paniagua et al. 1995; Ramsay et al. 2002; Joshua et al. 2010; see also Lagarde et al. 2002). Unlike the extended winter dormancy of G. agassizii (Nagy \& Medica 1986), P. geometricus are active each season (Boycott \& Bourquin 2000; Hofmeyr et al. 2012) and do not burrow. We need more data for winter and summer to understand all seasonal requirements.

Despite the high activity in autumn and spring, P. geometricus moved further, expressing greater habitat requirements, in autumn than in spring. Psammobates geometricus respond quickly to early autumn rains, being very active and drinking (current study, and BTH \& MDH, unpublished data). These responses likely supported subsequent foraging and the body condition increase from autumn to spring. Psammobates geometricus forage on new plant growth from autumn rains.

The greater distances travelled following early autumn rains may have also supported mating, as females begin ovulation in autumn ( $\mathrm{MDH}$, unpublished results). Rehydrating after summer rains stimulates activity, metabolic rate and water flux rates in G. agassizii (Henen 1997; Henen et al. 1998) and can support their autumn mating and pre-brumation vitellogenesis (Rostal 2014). In geometric tortoises however, most mating has been detected in summer - the dry season - before autumn rains fall. 


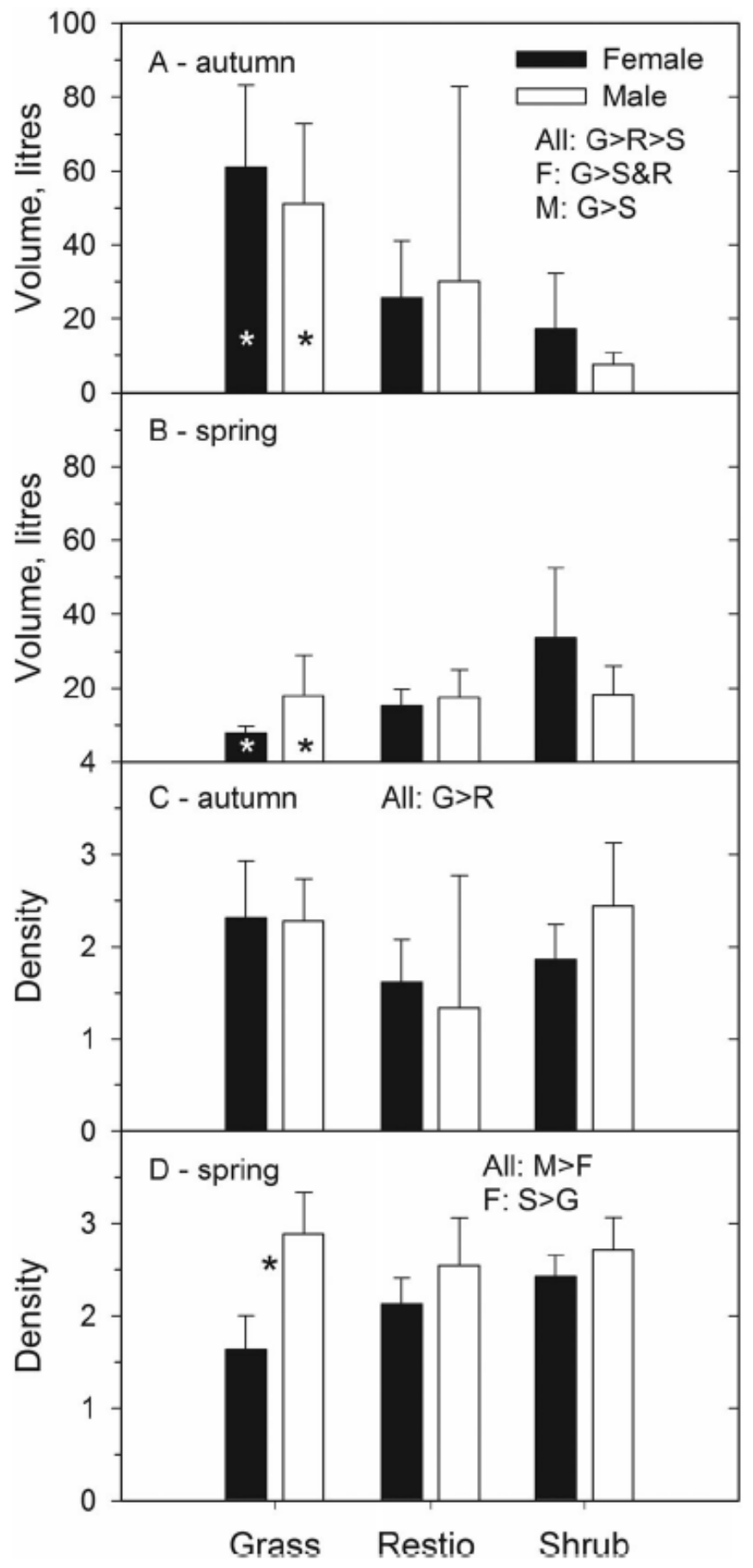

Figure 6. Volume (litres, A and B) and density (index, C and D) of grass (G), restio (R) and shrub (S) refuges of male (M) and female (F) geometric tortoises (Psammobates geometricus) in autumn (A and C) and spring (B and D) 2002. Autumn volumes were greater than spring volumes (autumn $36.0 \pm 9.1$ litres, $n=76$; spring $21.2 \pm 6.1, n=165$; two-way ANOVA $F_{1,237}=13.236, P<0.001$ ) and had no significant sex or interaction terms (both $F_{1,237}<0.2, P>0.65$ ). Autumn densities were lower than spring densities overall (autumn $2.07 \pm 0.215, n=76$; spring $2.45 \pm 0.146, n=$ 165; Mann-Whitney $U=4770.5, P=0.007)$ and for males $\left(H_{1}=4.25, P=0.039\right)$ but not for females $\left(H_{1}=0.051, P=0.822\right)$. Within-panel legends indicate refuge category or sex effects detected by post-hoc tests following Kruskal-Wallis one-way ANOVA on ranks (panel C) or twoway ANOVA (panels A and D). Grass volumes were larger in autumn than in spring (*, MannWhitney Rank Sum tests for each sex, $P \leq 0.002$ ). For grasses in spring, male refuges were denser than female refuges (panel $\mathrm{D} *$, significant post-hoc result). 


\section{Weather}

Weather effects manifested as seasonal and daily responses to rain and ground temperatures ( $\left.T_{\text {g-sun }}\right)$. On the three rainy days (22 and 23 April, 18 October, Fig. 1 ), all tortoises were active, which was higher than the average (Fig. 2). However, the distances moved on these three days differed between the two autumn days (59 and $68 \mathrm{~m}$, respectively) and the spring day $(19 \mathrm{~m})$. The $T_{\mathrm{g}}$-sun $\left(18.3{ }^{\circ} \mathrm{C}\right)$ during the spring rain was lower than $\mathrm{Tg}$-sun for the two rainy days in autumn (29.3 and $21.3{ }^{\circ} \mathrm{C}$, respectively), and may partially explain the relatively short distance moved on 18 October. However, these differences in movement distances were probably also affected by other factors such as body condition. In contrast to the high body condition that occurs in spring, the low body condition in autumn is a strong motivation for tortoises to move, drink and forage after the early autumn rains (see also Medica et al. 1980; Nagy \& Medica 1986; Henen 1997; Henen et al. 1998).

The relationship of daily movement to $T_{\mathrm{g}}$-sun indicates that habitat conditions affected geometric tortoise movements. As small, ground-dwelling, non-fossorial ectotherms, ground temperatures in the sun influenced female movements in autumn and male movements in spring (see also Keswick \& Hofmeyr 2014). Some tortoises may be inactive at low ambient temperatures (e.g. Gopherus berlandieri at $22{ }^{\circ} \mathrm{C}$, Rose \& Judd 1975; Chersina angulata at $14^{\circ} \mathrm{C}$, Ramsay et al. 2002), but the small size of P. geometricus (Table S1) would require less heat for basking and activity. Geometric tortoises are active during winter (Hofmeyr et al. 2012), and it would be useful to know what temperatures limit their activity.

\section{Refugia}

Psammobates geometricus use a diversity of perennial plants for refugia that provide cover from the physical elements and predators (Baard 1995). Refugia provide thermoregulatory benefits critical to many tortoise species (Bulova 2002; Lagarde et al. 2002 and 2012; Keswick \& Hofmeyr 2014; Moulherat et al. 2014) and male P. geometricus. Male refugia were most dense in spring, which is when male refugia were denser than female refugia and male movements were restricted by $T$ g-sun. Dense refugia in spring should alleviate some thermal stress on the males. By males being less active than females in spring, males spent more time in dense refugia when inactive for a day, and typically daytime temperatures are warmer than night-time temperatures.

Female P. geometricus used high-density shrub refugia in both seasons, but particularly in spring after primary production had increased the plants' solar reflectance (increased foliage to reflect radiation), solar absorbance (more foliage that is not translucent and may absorb light, e.g. to support photosynthesis), thermal insulation and plant biomass within the canopy's shadow (Louw \& Seely, 1982; Schlesinger et al. 1990). We did not quantify refuge availability to determine preferences, but a comparison of refuge use in our study with habitat composition data (Baard 1995) suggests geometric tortoises may prefer certain refuge types. Relative to Baard 1995 (subsequent values in brackets), our tortoises used more 
grasses than available (5-10\% cover), marginally more restioids than available $(10-25 \%$ cover), and shrubs within the range available (25-50\%).

As many tortoise species spend much of their life in refugia (up to 95\%, Nagy \& Medica 1986; Lagarde et al. 2002), and little time foraging each day (35 min. for Gopherus agassizii, Nagy \& Medica 1986; 52 min. for Kinixys spekii, Hailey \& Coulson 1999; <15 min. for T. horsfieldi, Lagarde et al. 2003; and 40 to $85 \mathrm{~min}$. for Chersina angulata, Keswick et al. 2006), much of their digestion, other metabolic activities (e.g. vitellogenesis and growth), and dormancy occur within the security of their refuges (Keswick et al. 2006; Keswick \& Hofmeyr 2014). Refuge use by these ectotherms should also be influenced by antipredator considerations. Consistent with antipredator considerations, and infrequent re-use of refugia by other tortoise species (Rose \& Judd 1975; Hailey 1989; Loehr 2002; Lagarde et al. 2012), geometric tortoises infrequently returned to the same refuge (once or $1 \%$ in autumn, nine times or $6 \%$ in spring) and tended to use dense refugia.

\section{Sex}

Despite the advantage of repeated measures statistics, we cautiously interpret sex effects because of the small sample sizes. Females sustained high activity in both seasons, consistent with supporting vitellogenesis, egg production, and their large bodies, relative to male size. However, the relatively low DDR of females is consistent with females finding sufficient food and refugia within small areas. The productivity of this ecosystem is high relative to that of arid ecosystems (Louw \& Seely 1982), where energy does not limit bigger tortoises (Henen 1997), so energy might not be a limiting resource for $P$. geometricus. However, we should analyse energy budgets (e.g. Nagy \& Medica 1986; Henen 1997) to determine whether energy is limiting for P.geometricus.

After reptiles become active (Bennett \& Nagy 1977), the increased cost due to moving and displacing far is inexpensive. This may partially explain the males' long movements and high DDR which will help males find and use resources (e.g. water, fresh food and mates). Other species of tortoise demonstrate the ability to learn (Simang et al. 2010) and be spatially aware of resources in their environment (Medica et al. 1980; Marlow \& Tollestrup 1982). If geometric tortoises are not energy- or food-limited, and males are smaller than females, the male bias for long and linear movements may reflect avoidance of other males' home ranges and reflect visiting the home ranges of more than one female.

\section{Acknowledgements}

This work partially fulfilled the MSc thesis requirements of Ulric P. van Bloemestein. We thank D. Parker (deceased), E. Parker and M. Gregor for permission to study tortoises at the reserve, CapeNature for permits (\# 280 and 1027), and Q. Joshua for assistance with fieldwork. We thank the Royal Society of London, the National Research Foundation (South Africa: 2039659) and the Senate at the University of the Western Cape (UWC) for funding (96/10/15). Our research was approved by the UWC Research Ethics Committee and followed "Guidelines for Use of Live Amphibians and Reptiles in Field Research", 
compiled by the American Society of Ichthyologists and Herpetologists, the Herpetologists' League and the Society for the study of Amphibians and Reptiles 2004.

\section{References}

BAARD, E.H.W. 1988. Psammobates geometricus: species report. South African Red Data Book. Reptiles and Amphibians. S. Afr. Nat. Sci. Programmes Rep. 151: 39-42.

BAARD, E.H.W. 1993. Distribution and status of the geometric tortoise Psammobates geometricus in South Africa. Biol. Conserv. 63: 235-239.

BAARD, E.H.W. 1995. A preliminary analysis of the habitat of the geometric tortoise Psammobates geometricus. S. Afr. J. Wildl. Res. 25: 8-13.

BENNETT, A.F. \& K.A. NAGY. 1977. Energy expenditure in free-ranging lizards. Ecology 58: 697-700. BOYCOTT, R.C. \& O. BOURQUIN. 2000. The Southern African Tortoise Book. A guide to southern African Tortoises, Terrapins and Turtles. O. Bourquin, Hilton, KwaZulu-Natal.

BREDER, R.B. 1927. Turtle trailing: a new technique for studying the life habits of certain Testudinata. N.Y. Zool. 9: 231-243.

BULOVA, S.J. 2002. How temperature, humidity, and burrow selection affect evaporative water loss in desert tortoises. J. Therm. Biol. 27: 175-189.

DIAZ-PANIAGUA, C., C. KELLER \& A.C. ANDREU. 1995. Annual variation of activity and daily distance moved in adult spur-thighed tortoises, Testudo graeca, in Southwestern Spain. Herpetologica 51: 225-233.

HAILEY, A. 1989. How far do animals move? Routine movements in a tortoise. Can. J. Zool. 67: 208- 215 .

HAILEY, A. \& I.M. COULSON. 1999. Measurements of time budgets from continuous observation of thread-trailing tortoises (Kinixys spekii). Herpetol. J. 9: 15-20.

HENEN, B.T. 1997. Seasonal and annual energy budgets of female desert tortoises (Gopherus agassizii). Ecology 78: 283-296.

HENEN, B.T., C.C. PETERSON, I.R. WALLIS, K.H. BERRY \& K.A. NAGY. 1998. Effects of climatic variation on field metabolism and water relations of desert tortoises. Oecologia 117: 365-373.

HENEN, B.T., M.D. HOFMEYR, R.A. BALSAMO \& F. WEITZ. 2005. Lessons from the food choices of the Endangered geometric tortoise, Psammobates geometricus. S. Afr. J. Sci. 101: 435-438.

HENEN, B.T., M.D. HOFMEYR \& E.H.W. BAARD. 2013. Body of evidence: forensic use of baseline health assessments to convict wildlife poachers. Wildl. Res. 40: 261-268.

HOFMEYR, M.D. \& E.H.W. BAARD. 2015. Psammobates geometricus. The IUCN Red List of Threatened Species 2015: e.T18398A76918966. https://doi.org/10.2305/IUCN.UK.2015-4. RLTS.T18398A76918966.en (accessed 13 March 2016).

HOFMEYR, M.D., B.T. HENEN \& E.H.W. BAARD. 2006. Conservation action plan for the Endangered geometric tortoise. Chelonii 4: 101-105.

HOFMEYR, M., U. VAN BLOEMESTEIN, B. HENEN \& C. WEATHERBY. 2012. Sexual and environmental variation in the space requirements of the Critically Endangered geometric tortoise, Psammobates geometricus. Amph.-Rept. 33: 185-197. 
JOSHUA, Q.I., M.D. HOFMEYR \& B.T. HENEN. 2010. Seasonal and site variation in angulate tortoise diet and activity. J. Herpetol. 44: 124-134.

KESWICK, T. \& M. HOFMEYR. 2014. Refuge characteristics and preferences of Psammobates oculifer in semi-arid savanna. Amph.-Rept. 35: 41-51.

KESWICK, T., B.T. HENEN \& M.D. HOFMEYR. 2006. Sexual disparity in activity patterns and time budgets of angulate tortoises (Chersina angulata) on Dassen Island, South Africa. Afr. Zool. 41: 224-233.

LAGARDE, F., X. BONNET, J. CORBIN, B.T. HENEN \& K.A. NAGY. 2002. A short spring for a long jump: the ecological challenge for the Steppe tortoise (Testudo horsfieldi). Can. J. Zool. 80: 493-502.

LAGARDE, F., X. BONNET, J. CORBIN, B. HENEN, K. NAGY, B. MARDONOV \& G. NALLEAU. 2003. Foraging behaviour and diet of an ectothermic herbivore: Testudo horsfieldi. Ecography 26: 236-242.

LAGARDE F., T. LOUZIZI, T. SLIMANI, H. EL MOUDEN, K. BEN KADDOUR, S. MOULHERAT \& X. BONNET. 2012. Bushes protect tortoises from lethal overheating in arid areas of Morocco. Environ. Conserv. 39: 172-182.

LOEHR, V.J.T. 2002. Population characteristics and activity patterns of the Namaqualand speckled padloper (Homopus signatus signatus) in early spring. J. Herpetol. 36: $378-389$.

LOEHR, V.J.T., B.T. HENEN \& M.D. HOFMEYR. 2004. Reproduction of the smallest tortoise, the Namaqualand speckled padloper, Homopus signatus signatus. Herpetologica 60: 444-454.

LOUW, G.N. \& M.K. SEELY. 1982. Ecology of Desert Organisms. Longman, New York.

MARLOW, R.W. \& K. TOLLESTRUP. 1982. Mining and exploitation of natural mineral deposits by the desert tortoise, Gopherus agassizii. Anim. Behav. 30: 475-478.

MEDICA, P.A., R.B. BURY \& R.A. LUCKENBACH. 1980. Drinking and construction of water catchments by the desert tortoise, Gopherus agassizii, in the Mojave Desert. Herpetologica 1980: 301-304.

MOULHERAT, S., V. DELMASA, T. SLIMANI, E.H. EL MOUDEN, T. LOUZIZI, F. LAGARDE \& X. BONNET. 2014. How far can a tortoise walk in open habitat before overheating? Implications for conservation. J. Nat. Conserv. 22: 186-192.

NAGY, K.A. \& P.A. MEDICA. 1986. Physiological ecology of desert tortoises in southern Nevada. Herpetologica 42: 73-92.

RAMSAY, S.L., M.D. HOFMEYR \& Q.I. JOSHUA. 2002. Activity patterns of the angulate tortoise (Chersina angulata) on Dassen Island, South Africa. J. Herpetol. 36: 161169.

ROSE, F.I. \& F.W. JUDD. 1975. Activity and home range size of the Texas tortoise, Gopherus berlandieri, in South Texas. Herpetologica 31: 448-456.

ROSTAL, D.C. 2014. Reproductive physiology of North American tortoises. In D.C. ROSTAL, E.D. MCCOY \& H.R. MUSHINSKY (Eds), Biology and Conservation of North American Tortoises. Johns Hopkins University Press, Baltimore, MD.

SCHLESINGER, W.H., J.F. REYNOLDS, G.L. CUNNINGHAM, L. F. HUENNEKE, W.M. JARRELL, R.A. VIRGINIA \& W.G. WHITFORD. 1990. Biological feedbacks in global desertification. Science 247: 1043-1048. 
SIMANG, A., P.L. CUNNINGHAM \& B.T. HENEN. 2010. Color selection by juvenile leopard tortoises (Stigmochelys pardalis) in Namibia. J. Herpetol. 44: 327-331.

TIME AND DATE AS. 2016. Cape Town, South Africa. http://www.timeanddate.com/sun/south-africa/ cape-town (accessed 18 September 2016).

WRIGHT, J., E. STEER \& A. HAILEY. 1988. Habitat separation in tortoises and the consequence for activity and thermoregulation. Can. J. Zool. 66: 1537-1544.

ZAR, J.H. 1999. Biostatistical Analysis, 4th edn. Prentice-Hall, Upper Saddle River, NJ. 